\title{
Ophthalmic outcomes following neonatal hypoxic ischaemic encephalopathy; oculomotor, biometric and refractive data in early childhood
}

\author{
Mark James $^{1,2} \cdot$ Catherine M. $\mathrm{O}^{\prime}$ Connor $\mathbb{1}^{3,4} \cdot$ Anthony Cullinane ${ }^{2} \cdot$ Deirdre M. Murray ${ }^{3,4} \cdot$ Geraldine B. Boylan ${ }^{3,4}$
}

Received: 30 September 2018 / Revised: 11 February 2019 / Accepted: 20 February 2019 / Published online: 5 March 2019

(c) The Royal College of Ophthalmologists 2019

\begin{abstract}
Objectives To investigate the functional and structural impact of neonatal hypoxic ischaemic encephalopathy (HIE) on childhood visual development.

Methods In a prospective study, the neurocognitive outcomes of 42 children with a history of neonatal HIE were assessed serially up to 5 years. For the ophthalmic component of the study, visual, refractive, orthoptic and ocular biometry measurements were obtained in 32 children, with axial length measurements estimated using the IOLMaster.

Results For the 32 children who completed the ophthalmic component of the study, severity of HIE grade was determined to be mild, moderate, or severe in $18(56.3 \%), 13(40.6 \%)$, and $1(3.1 \%)$ cases, respectively. One (3.1\%) child was classed as visually impaired. Twelve $(37.5 \%)$ were found to have ametropia. Mean $( \pm \mathrm{SD})$ axial length was $22.09( \pm 0.81) \mathrm{mm}$, within the normal range for the age of this cohort. Seven of the $42(16.7 \%)$ children who were involved in the larger neurodevelopmental arm of the study had clinical evidence of a squint. There was no correlation between the severity of HIE grade at birth and axial length or occurrence of squint.

Conclusions Neonatal HIE is associated with a higher incidence of squint compared with the general paediatric population. This occurred irrespective of severity of HIE grade. The ocular biometry measurements were consistent with published normative data, and no significant difference in ocular biometry was demonstrated between HIE severity groups.
\end{abstract}

\section{Introduction}

Neonatal hypoxic ischaemic encephalopathy (HIE) remains one of the commonest causes of acquired neonatal brain injury, affecting approximately three per 1000 term births in the developed world with a rate ten times higher in the developing world [1]. Visual loss is frequently associated with neurological disability making perinatal HIE, in term and preterm infants, the most common cause of visual

Mark James

m.james@ucc.ie

Medical Education Unit, University College Cork, Cork, Ireland

2 Department of Ophthalmology, Cork University Hospital, Cork, Ireland

3 Department of Paediatrics and Child Health, University College Cork, Cork, Ireland

4 Irish Centre for Fetal and Neonatal Translational Research, Cork, Ireland disability in developed countries [2]. While damage to the primary visual cortex, visual associative cortex, optic radiations, optic nerves or visual attention pathways can occur [2], the mechanism of injury and prognosis for recovery is usually unclear [3].

Head growth in early life can be related to the severity of the initial hypoxic insult, and result in suboptimal growth and consequent microcephaly [4]. This may have ophthalmic implications as generally the growth pattern of the eye mirrors that of the brain $[5,6]$. Most of the postnatal growth of the eye occurs within the first 3 years of life, with a rapid phase acceleration evident from birth to 6 months of age $[7,8]$. It is uncertain whether perinatal ischaemic injury has a negative effect on early ocular growth rate similar to the restriction in brain growth. There is a correlation between the impact of HIE on early visual function and subsequent neuromotor development [9], with increased rates of strabismus usually explained in terms of concomitant motor difficulties and/or cerebral palsy [10].

Few studies have followed the visual outcome of children with neonatal HIE to school age so limited outcome 
data are available. Furthermore, to the best of our knowledge, none have previously reported detailed ocular biometry. In this paper we report on the ophthalmic outcomes, including visual, refractive, orthoptic and ocular biometry measurements of a carefully defined prospective cohort of children with neonatal HIE.

\section{Subjects and methods}

Term infants with suspected HIE were recruited between May 2003 and December 2005 from the regional maternity service. Inclusion and exclusion criteria for the study, as well as the 2 years and 5 years neurodevelopmental outcome of this cohort has been previously reported [11, 12]. Each infant was assigned a modified Sarnat encephalopathy grade at $24 \mathrm{~h}$ and HIE grade was confirmed on serial EEG recordings [13, 14]. This is an 'uncooled' cohort due to being recruited in the pre-therapeutic hypothermia era.

The current study was part of this longitudinal study which followed the neurodevelopmental progress of these children to 5 years and was approved by the Clinical Research Ethics Committee of the Cork Teaching Hospitals. Research protocols were in keeping with the tenets of the Declaration of Helsinki. Parents or carers of the children in the HIE birth cohort from age 3 years onwards were contacted and written informed consent for the ophthalmic component of the study was obtained.

During their ophthalmic assessment, data recorded for each participant were classed as demographic, clinical, visual, orthoptic, biometric, and refractive. Clinical data included: general medical history; family history of ocular disorders; birth weight $(\mathrm{kg})$; occipito-frontal circumference $(\mathrm{OFC})(\mathrm{cm})$; HIE grade; and anterior segment and fundal findings on slit lamp biomicroscopy. Visual data included: Snellen, $\log$ MAR, or Sheridan-Gardner visual acuity as appropriate; and confrontation visual fields assessment by the use of a target gradually moved in from the periphery until detected. Orthoptic data were assessed by an experienced orthoptist (BH), and included: ocular alignment on cover testing; angle of squint by prism cover testing; ocular motility, including convergence; and stereopsis determination by the Lang II stereo test.

All biometric and refractive measurements were performed by a single ophthalmologist (MJ). Children underwent both cycloplegic autorefraction and streak retinoscopy, from which the spherical equivalent (SE) refractive error for each eye was calculated. Ametropia was defined as SE refraction of $\geq+2.0$ dioptres (D) or $\leq-0.5 \mathrm{D}$ in either eye, or astigmatism of $\geq 1.5 \mathrm{D}$. Ocular biometry using the IOLMaster (Carl Zeiss Meditec, Jena, Germany) was used to obtain average axial length $(\mathrm{mm})$ and keratometry values (expressed as the mean of the steepest and flattest meridian in (D)).

Visual impairment was defined as a visual acuity (unaided or with glasses if worn) of less than $6 / 12$ in the better seeing eye. Anisometropia was defined as an interocular difference in SE of $\geq 1.0$ D. As there were no statistically significant differences between refractive and ocular biometry data between right and left eyes, all subsequent analyses used data from a single eye in each case following randomisation. Ocular data were analysed using Stata package ver. 8.0 (StataCorp. 2005; Stata Statistical Software: Release 9.0; College Station, TX). The associations between the categorical variables were examined using the Chi-square test, and the Mann-Whitney $U$-test was used for continuous variables. Statistical significance was set at $P$-value $<0.05$.

\section{Results}

Of the 42 children included in the study, parents of 33 children agreed to allow them to participate in detailed ophthalmological examinations, while the remaining nine did not wish to return for assessment, but agreed to a review of their existing ophthalmology notes. Two (22.2\%) of these nine children had known ophthalmic issues (both with moderate HIE and previously diagnosed squint), while there were no visual concerns reported for the other seven.

Of the 33 children available for detailed ophthalmological examination, one child with severe HIE at birth and severe cerebral palsy was unable to co-operate with biometric measurements; however, no gross squint or significant refractive error was noted. Thus, complete ophthalmological assessments were available in 32 children. The mean age $( \pm \mathrm{SD})$ at ophthalmic examination was $61.0( \pm 9.2)$ months, (range: $40-76$ months). Details relating to HIE grade and birth parameters are shown in Table 1 . There were two $(6.3 \%)$ children with an OFC below the $3^{\text {rd }}$ centile, one with mild and one with moderate HIE.

Normal visual fields were found in 27 (84.4\%) children, while the remaining five (15.6\%) had no obvious defect, but had insufficient co-operation to allow reliable assessment. A visual acuity in either eye of $6 / 12$ or better was documented in $31(96.9 \%)$ children, and 6/6 or better in $29(90.6 \%)$. One (3.1\%) child was classed as visually impaired, with a visual acuity of $6 / 18$ in each eye in the absence of any significant refractive error or ocular pathology. Two (6.3\%) children were noted to have an amblyopic eye, with a visual acuity of $6 / 12$ or worse, secondary to anisometropia.

A summary of abnormal ocular outcomes by HIE grade for the 32 children who attended for the full ophthalmic section of the study is displayed in Table 2. Five (15.6\%) children had evidence of a manifest squint: two had 
accommodative esotropia with hyperopia; another three had divergent strabismus with no significant refractive error but had a positive family history of squint. There was no statistically significant difference in strabismus rates between the HIE grades $(P=1.0)$. The refractive error, angle of squint, and other notable associations are detailed in Table 3. This includes two additional children who had a diagnosis of squint documented in their medical notes from the larger cohort of 42, but did not partake in the full ophthalmic assessment arm of the study, bringing the total number of children with confirmed squint from the whole cohort to seven $(16.7 \%)$.

No statistically significant difference between refractive data achieved through autorefraction and that from retinoscopy was noted $(P>0.05)$. Following randomisation, mean

Table 1 Details of birth parameters by HIE grade for children who attended for ophthalmic examination

\begin{tabular}{|c|c|c|c|c|}
\hline & \multicolumn{3}{|l|}{ HIE grade } & \multirow[t]{2}{*}{$P$-value } \\
\hline & Mild & Moderate & Severe & \\
\hline \multicolumn{5}{|l|}{ Gender } \\
\hline Male, $n(\%)$ & $13(61.9)$ & $7(33.3)$ & $1(4.8)$ & \\
\hline Female, $n(\%)$ & $5(45.5)$ & $6(54.5)$ & $0(0.0)$ & \\
\hline All, $n(\%)$ & $18(56.3)$ & $13(40.6)$ & $1(3.1)$ & 0.29 \\
\hline \multicolumn{5}{|l|}{ Birth weight $(\mathrm{kg})$} \\
\hline Median (range) & $3.57(2.08-4.04)$ & $3.30(1.83-4.2)$ & 3.43 & 0.56 \\
\hline $\begin{array}{l}\text { Low birth weight, } \\
* * n(\%)\end{array}$ & $2(11.1)$ & $1(7.7)$ & $0(0)$ & \\
\hline \multicolumn{5}{|c|}{ Head circumference $(\mathrm{cm})$} \\
\hline Median (range) & $36(32-40)$ & $36(31.5-37.4)$ & 36.8 & 0.53 \\
\hline
\end{tabular}

* $P$-value relates to mild and moderate HIE groups

**Birth weight less than $2.5 \mathrm{~kg}$

Table 2 Summary of ocular findings for children who attended the full ophthalmic section of the study, including refractive and ocular biometry data of the randomised eye by severity of HIE grade
$( \pm \mathrm{SD})$ SE refractive error was $+1.69( \pm 1.5) \mathrm{D}$, with a range of $-0.625 \mathrm{D}$ to $+6.75 \mathrm{D}$. Mean astigmatism was +0.6 $( \pm 0.7) \mathrm{D}$, with a range from $0 \mathrm{D}$ to $3.75 \mathrm{D}$. In total, $12 / 32$ $(37.5 \%)$ children were found to have ametropia; one child (3.1\% of sample) was classed as myopic, nine $(28.1 \%)$ as hyperopic, three $(9.4 \%)$ as having astigmatism (of whom one was also hyperopic). Two $(6.3 \%)$ children were noted to have anisometropia (both were also in the hyperopic group).

Analysing ocular biometry data from each of the randomised eyes (Table 2$)$, the mean $( \pm \mathrm{SD})$ axial length was 22.09 $( \pm 0.81) \mathrm{mm}$ (range, 20.63-24.77 $\mathrm{mm}$ ). There was a positive correlation between axial length and age $($ rho $=0.4919)$, with children over 60 months of age having a statistically significant longer median axial length than those under 60 months $(P=0.039)$. Otherwise, there were no statistically significant differences between the ocular biometric parameters (axial length, SE, or keratometry) and age, sex or HIE grade (mild versus moderate) on univariate analysis.

\section{Discussion}

We have described the detailed ophthalmic outcomes of a prospective cohort of children following neonatal HIE, who were born prior to the introduction of therapeutic hypothermia for moderate-severe HIE. A recent Cochrane review of the effects of therapeutic hypothermia in the management of neonatal HIE suggested a non-significant reduction in blindness in infants who were cooled [15]. The randomised controlled trials reviewed focused on infants with moderate to severe encephalopathy only, whereas our data adds

\begin{tabular}{|c|c|c|c|c|c|}
\hline & \multicolumn{4}{|l|}{ HIE grade } & \multirow[t]{2}{*}{$P$-value* } \\
\hline & Mild, $n=18$ & Moderate, $n=13$ & $\begin{array}{l}\text { Severe, } \\
n=1\end{array}$ & All grades, $n=32$ & \\
\hline Visual acuity $\leq 6 / 18, n(\%)$ & $1(5.6)$ & $0(0)$ & $0(0)$ & $1(3.1)$ & 1.0 \\
\hline $\begin{array}{l}\text { Presence of strabismus**, } \\
n(\%)\end{array}$ & $3(16.7)$ & $2(15.4)$ & $0(0)$ & $5(15.6)$ & 1.0 \\
\hline $\begin{array}{l}\text { Keratometry (D), mean } \\
( \pm \text { SD) }\end{array}$ & $43.15( \pm 1.66)$ & $43.26( \pm 1.24)$ & 42.61 & $43.20^{\dagger}( \pm 1.45)$ & 0.83 \\
\hline $\begin{array}{l}\text { SE refractive error }(D), \\
\text { mean }( \pm S D)\end{array}$ & $+1.99( \pm 1.72)$ & $+1.46( \pm 0.97)$ & -0.63 & $+1.69( \pm 1.50)$ & 0.21 \\
\hline \multicolumn{6}{|c|}{ Axial length (mm), mean $( \pm S D)$} \\
\hline Age range: $40-60$ months & $21.62( \pm 0.75)$ & $21.85( \pm 0.55)$ & 22.04 & $21.74( \pm 0.64)$ & \\
\hline Age range: $61-76$ months & $22.52( \pm 1.01)$ & $22.22( \pm 0.48)$ & & $22.40( \pm 0.82)^{\ddagger}$ & \\
\hline All ages & $22.12( \pm 0.99)$ & $22.05( \pm 0.53)$ & 22.04 & $22.09( \pm 0.81)$ & 0.81 \\
\hline
\end{tabular}

$D$ diopters, $S E$ spherical equivalent

$* P$-value relates to mild and moderate HIE groups

**Strabismus defined as the presence of a manifest deviation on cover testing

tEquivalent to a mean corneal radius of curvature of $7.81 \mathrm{~mm}$

${ }^{\ddagger} P=0.039$ with respect to the difference in mean axial length between the age groups 
Table 3 Subgroup characteristics of children who had manifest strabismus

\begin{tabular}{lllllllll}
\hline$\#$ & Gender & $\begin{array}{l}\text { Age } \\
\text { (months) }\end{array}$ & HIE grade & Squint type $\begin{array}{l}\text { Angle of squint } \\
\text { at } 1 / 3 \mathrm{~m} \\
\text { (prism diopters) }\end{array}$ & $\begin{array}{l}\text { Lang stereo } \\
\text { test }\end{array}$ & $\begin{array}{l}\text { SE refractive } \\
\text { error (D)* }\end{array}$ & $\begin{array}{l}\text { Other visual } \\
\text { findings }\end{array}$ \\
\hline 1 & Female & 74 & Mild & Exotropia & 12 & $4 / 4$ & +1.125 & Convergence insufficiency \\
2 & Male & 76 & Mild & Esotropia & 20 & $4 / 4$ & +1.875 & Saccades initiation failure \\
3 & Male & 47 & Mild & Exotropia & 45 & $4 / 4$ & +2.375 & +1.75 \\
4 & Female & 61 & Moderate & Exotropia & 20 & $4 / 4$ & +4.625 & \\
5 & Male & 60 & Moderate & Esotropia & 12 & $4 / 4$ & $* *$ & \\
$6^{* *}$ & Female & $* *$ & Moderate & Exotropia & $* *$ & $* *$ & $* *$ & \\
$7 * *$ & Female & $* *$ & Moderate & Exotropia & $* *$ & $* *$ & $* *$ & \\
\hline
\end{tabular}

$D$ diopters, $S E$ spherical equivalent

*SE refractive error is of the eye with the greater refractive error

**These two additional children with a confirmed history of squint from orthoptist notes were participants of the main HIE study group, but were not from the 32 who attended for the full ophthalmic assessment part of the study. As a result, some of their ocular and refractive data are omitted

significantly to the limited knowledge that is available for outcomes following mild HIE.

Visual impairment in early life interferes with visual exploration at a critical time of neuronal maturation in the occipital lobes, and has been shown to have a negative impact on visual function at school age $[16,17]$. The prevalence rate of visual impairment in Caucasian children of seven years of age in a British population-based study was found to be $0.5 \%$ [17]. While higher than this, the rate of visual impairment in our study would still be considered low $(3.1 \%)$, with no child having clinically observable restriction of their visual fields, and only one child found to have visual impairment where acuity was worse than $6 / 12$ in both eyes. This child had mild HIE, but had no significant refractive or other ocular cause for reduced vision, raising the possibility of cortical impairment or injuries to the inner retina $[18,19]$. The rate of adverse visual outcomes in our study was lower than those found by Mercuri et al. [16], which may be due to differences between the cohorts with respect to Apgar criteria, classification and severity of HIE grade. Our cohort included those with mild HIE who would be expected to have a better outcome. In addition, at 5 years, very few children with severe grade HIE were still alive, or able to co-operate for a complete examination due to severe motor or intellectual difficulties.

Consistent with other studies showing increased risk of strabismus in school aged children with a history of neonatal encephalopathy $[16,20]$, our incidence of manifest squint of $16.7 \%$ exceeds that which would be expected in a healthy childhood population of between 1.5 and $2.8 \%$ [17, 21-23]. One explanatory hypothesis proposes that adverse intrauterine and perinatal events during a critical period of brain development may disrupt the prenatal programming of coordination and control of eye movements [22]. Cerebral visual impairment of hypoxic ischaemic origin is associated with higher rates of ocular motility disorders, including saccadic initiation failure, absence of pursuit, nystagmus, and variable angle squint [24, 25].

Our cohort was predominantly white European, whose mean SE refractive error of $+1.69 \mathrm{D}$ is close to that found in both a Spanish and an American study involving healthy Caucasian children of an equivalent age [26, 27]. Additionally, rates of myopia and hyperopia in our study were similar to that found in population-based data involving Northern Irish children with a comparable age and race profile [28]. Therefore, it appears that mild and moderate HIE does not confer any additional risk with respect to the development of refractive error in early childhood.

There are well-established links between biometric measurements of the eye and brain, with respect to size and growth rates [5, 6]. Axial length increases with age in the paediatric population $[7,8]$, so it is unsurprising that there was a significant difference in axial length comparing those under and over the age of 5 years. However, we found no correlation between axial length measurements and severity of HIE grade in our cohort of children with mostly mild and moderate HIE. Indeed, the mean axial length in our cohort of $22.09 \mathrm{~mm}$ is close to the expected normative value from a published algorithm for early eye growth [7], and similar to that noted in a group of healthy Spanish Caucasian children of an equivalent age [27]. Mean keratometric measurements were also similar to what would be expected in this age group [29].

One of the strengths of our study was the inclusion of ocular biometry data measured with the IOLMaster, which is reported to be superior to ultrasound, and should be the standard for the precision and repeatability of axial length measurements in children [30]. A limitation of our study was the absence of serial axial length measurements from an earlier age in each child. However, co-operation with 
detailed ocular examinations at a younger age is difficult to achieve and less acceptable to parents [8]. Therefore, we cannot rule out a delay in early ocular growth rates before reaching this end point, or if the resulting excess hypermetropia and visual blur may have acted to reverse this trend and stimulate growth in support of an active model of emmetropization [31]. Also, as only two of the children in our cohort had microcephaly, we could not determine whether ocular axial length was restricted in a similar way to that of brain growth. Neither could we confirm whether birth parameters such as gestational age and birth weight have an impact on ocular biometry results, as only full-term babies were included in our cohort, and just three had low birth weight.

Although children with severe HIE would be more likely to have microcephaly and possibly shorter axial lengths, there are difficulties in recruiting and retaining this cohort due to the high rate of mortality and disability. However, this remains, to our knowledge, the largest prospective study of ophthalmic outcomes in a HIE cohort, and the only one with detailed ocular biometric data. In conclusion, we found no increase in refractive error or change in ocular axial length measurements in surviving children with a history of neonatal HIE. We have confirmed a higher rate of squint in this cohort, in both mild and moderate HIE. Therefore, we suggest that infants with HIE of any grade should undergo an ophthalmic assessment in early childhood as part of their overall neurodevelopmental follow-up.

\section{Summary}

\section{What was known before}

- Impact of neonatal hypoxic ischaemic encephalopathy (HIE) on ophthalmic outcomes: There is a correlation between the impact HIE has on early visual function and subsequent neuromotor development, with increased rates of strabismus.

- Impact of neonatal HIE on brain growth: Head growth in early life can be related to the severity of the initial hypoxic insult, and result in suboptimal growth and consequent microcephaly. The growth pattern of the eye mirrors that of the brain.

\section{What this study adds}

- Visual outcome of children with neonatal HIE followed up to school age: The rate of visual impairment in children with predominantly mild to moderate HIE is low.
- Refractive and ocular biometry outcome: There is no increase in refractive error or change in ocular axial length measurements in surviving children with a history of neonatal HIE.

- Strabismus rates: There is a higher rate of squint in this cohort, in both mild and moderate HIE, suggesting that infants with HIE of any grade should undergo an ophthalmic assessment in early childhood as part of their overall neurodevelopmental follow-up.

Acknowledgements We wish to thank Ms Beatrix Haskins, Senior Orthoptist for the Health Service Executive South, for her dedication and expertise in assessing visual performance and detecting strabismus in the cohort of children involved in this study. We would also like to acknowledge the parents, caregivers, and children who gave their time to the study.

Funding Funding for the broader neurodevelopmental arm of the study was received from the Health Research Board.

\section{Compliance with ethical standards}

Conflict of interest The authors declare that they have no conflict of interest.

Publisher's note: Springer Nature remains neutral with regard to jurisdictional claims in published maps and institutional affiliations.

\section{References}

1. Volpe JJ. Neurology of the newborn. Fifth ed. Philadelphia, PA: Saunders; 2008.

2. Hoyt CS. Brain injury and the eye. Eye. 2007;21:1285-9.

3. Casteels I, Demaerel P, Spileers W, Lagae L, Missotten L, Casaer P. Cortical visual impairment following perinatal hypoxia: clinicoradiologic correlation using magnetic resonance imaging. J Pediatr Ophthalmol Strabismus. 1997;34: 297-305.

4. Mercuri E, Ricci D, Cowan FM, Lessing D, Frisone MF, Haataja $\mathrm{L}$, et al. Head growth in infants with hypoxic-ischemic encephalopathy: correlation with neonatal magnetic resonance imaging. Pediatrics. 2000;106(2 Pt 1):235-43.

5. Denis D, Righini M, Scheiner C, Volot F, Boubli L, Dezard X, et al. Ocular growth in the fetus. 1. Comparative study of axial length and biometric parameters in the fetus. Opthalmologica. 1993;207:117-24.

6. Saw S-M, Tong L, Chia K-S, Koh D, Lee Y-S, Katz J, et al. The relation between birth size and the results of refractive error and biometry measurements in children. $\mathrm{Br} \mathrm{J}$ Ophthalmol. 2004;88:538-42.

7. Fledelius HC, Christensen AC. Reappraisal of the human ocular growth curve in fetal life, infancy, and early childhood. Br J Ophthalmol. 1996;80:918-21.

8. Pennie FC, Wood ICJ, Olsen C, White S, Charman WN. A longitudinal study of the biometric and refractive changes in fullterm infants during the first year of life. Vision Res. 2001:41:2799-810. 
9. Mercuri E, Haataja L, Guzzetta A, Anker S, Cowan F, Rutherford $\mathrm{M}$, et al. Visual function in term infants with hypoxic-ischaemic insults: correlation with neurodevelopment at 2 years of age. Arch Dis Child Fetal Neonatal Ed. 1999;80:F99-F104.

10. Martinez-Biarge M, Diez-Sebastian J, Rutherford MA, Cowan FM. Outcomes after central grey matter injury in term perinatal hypoxicischaemic encephalopathy. Early Hum Dev. 2010;86:675-82.

11. Murray DM, Boylan GB, Ryan CA, Connolly S. Early EEG findings in hypoxic-ischemic encephalopathy predict outcomes at 2 years. Pediatrics. 2009;124:e459-e67.

12. Murray DM, O'Connor CM, Ryan CA, Korotchikova I, Boylan GB. Early EEG grade and outcome at 5 years following mild neonatal hypoxic ischemic encephalopathy. Pediatrics. 2016;138: e20160659.

13. Sarnat HB, Sarnat MS. Neonatal encephalopathy following fetal distress. A clinical and electroencephalographic study. Arch Neurol. 1976;33:696-705.

14. Levene MI, Kornberg J, Williams THC. The incidence and severity of post-asphyxial encephalopathy in full-term infants. Early Hum Dev. 1985;11:21-6.

15. Jacobs SE, Berg M, Hunt R, Tarnow-Mordi WO, Inder TE, Davis PG. Cooling for newborns with hypoxic ischaemic encephalopathy. Cochrane Database Syst Rev. 2013;CD003311.

16. Mercuri E, Anker S, Guzzetta A, Barnett AL, Haataja L, Rutherford M, et al. Visual function at school age in children with neonatal encephalopathy and low Apgar scores. Arch Dis Child Fetal Neonatal Ed. 2004;89:F258-F62.

17. Williams C, Northstone K, Howard M, Harvey I, Harrad RA, Sparrow JM. Prevalence and risk factors for common visual problems in children: data from the ALSPAC study. Br J Ophthalmol. 2008;92:959-64.

18. Jung S, Polosa A, Lachapelle P, Wintermark P. Visual impairments following term neonatal encephalopathy: do retinal impairments also play a role? Invest Ophthalmol Vis Sci. 2015;56:5182-93.

19. Chan KC, Kancherla S, Fan S-J, Wu EX. Long-term effects of neonatal hypoxia-ischemia on structural and physiological integrity of the eye and visual pathway by multimodal MRI. Invest Ophthalmol Vis Sci. 2015;56:1-9.

20. Moster D, Lie RT, McCormick MC, Markestad T. Joint association of Apgar scores and early neonatal symptoms with minor disabilities at school age. Arch Dis Child Fetal Neonatal Ed. 2002;86:F16-F21.

21. Stayte M, Johnson A, Wortham C. Ocular and visual defects in a geographically defined population of 2-year-old children. $\mathrm{Br} \mathrm{J}$ Ophthalmol. 1990;74:465-8.

22. Pathai S, Cumberland PM, Rahi JS. Prevalence of and early-life influences on childhood strabismus: findings from the Millennium Cohort Study. Arch Pediatr Adolesc Med. 2010;164:250-7.

23. Robaei D, Rose KA, Kifley A, Cossick M, Ip JM, Mitchell P. Factors associated with childhood strabismus: findings from a population-based study. Ophthalmology. 2006;113:1146-53.

24. Salati R, Borgatti R, Giammari G, Jacobson L. Oculomotor dysfunction in cerebral visual impairment following perinatal hypoxia. Dev Med Child Neurol. 2002;44:542-50.

25. Pehere N, Chougule P, Dutton GN. Cerebral visual impairment in children: causes and associated ophthalmological problems. Indian J Ophthalmol. 2018;66:812-5.

26. Giordano L, Friedman DS, Repka MX, Katz J, Ibironke J, Hawes $\mathrm{P}$, et al. Prevalence of refractive error among preschool children in an urban population: the Baltimore Pediatric Eye Disease Study. Ophthalmology. 2008;116:739-46.

27. Barrio-Barrio J, Noval S, Galdos M, Ruiz-Canela M, Bonet E, Capote M, et al. Multicenter Spanish study of spectral-domain optical coherence tomography in normal children. Acta Ophthalmol. 2013;91:e56-e63.

28. O'Donoghue L, McClelland JF, Logan NS, Rudnicka AR, Owen CG, Saunders KJ. Refractive error and visual impairment in school children in Northern Ireland. $\mathrm{Br} \mathrm{J}$ Ophthalmol. 2010;94:1155-9.

29. Ojaimi E, Rose KA, Morgan IG, Smith W, Martin FJ, Kifley A, et al. Distribution of ocular biometric parameters and refraction in a population-based study of Australian children. Invest Ophthalmol Vis Sci. 2005;46:2748-54.

30. Carkeet A, Saw S-M, Gazzard G, Tang W, Tan DTH. Repeatability of IOLMaster biometry in children. Optom Vis Sci. 2004;81:829-34.

31. Mutti DO, Mitchell GL, Jones LA, Friedman NE, Frane SL, Lin $\mathrm{WK}$, et al. Axial growth and changes in lenticular and corneal power during emmetropization in infants. Invest Ophthalmol Vis Sci. 2005;45:3074-80. 